\title{
Impact of Sequential Therapy With Osimertinib on the Overall Survival in Patients With EGFR-mutant Non-small Cell Lung Cancer
}

\author{
Minehiko Inomata ( 9446-tym@umin.org ) \\ Toyama Daigaku Fuzoku Byoin https://orcid.org/0000-0002-6846-187X
}

Masahiro Matsumoto

Toyama Daigaku Fuzoku Byoin

Isami Mizushima

Toyama Daigaku Fuzoku Byoin

Kana Hayashi

Toyama Daigaku Fuzoku Byoin

\section{Zenta Seto}

Toyama Daigaku Fuzoku Byoin

Kotaro Tokui

Toyama Daigaku Fuzoku Byoin

Chihiro Taka

Toyama Daigaku Fuzoku Byoin

Seisuke Okazawa

Toyama Daigaku Fuzoku Byoin

Kenta Kambara

Toyama Daigaku Fuzoku Byoin

Shingo Imanishi

Toyama Daigaku Fuzoku Byoin

Toshiro Miwa

Toyama Daigaku Fuzoku Byoin

Ryuji Hayashi

Toyama Daigaku Fuzoku Byoin

Shoko Matsui

Toyama Daigaku Fuzoku Byoin

Kazuyuki Tobe

Toyama Daigaku Fuzoku Byoin 
Keywords: epidermal growth factor receptor, tyrosine kinase inhibitor, lung cancer, osimertinib, survival, prognosis

Posted Date: July 28th, 2021

DOI: https://doi.org/10.21203/rs.3.rs-747775/v1

License: (c) (1) This work is licensed under a Creative Commons Attribution 4.0 International License. Read Full License

Version of Record: A version of this preprint was published at The Egyptian Journal of Bronchology on March 20th, 2022. See the published version at https://doi.org/10.1186/s43168-022-00121-1. 


\section{Abstract}

Purpose. We conducted a retrospective analysis of the data of patients with epidermal growth factor receptor (EGFR)-mutant non-small cell lung cancer (NSCLC) to investigate the associations between the available treatment options and the overall survival.

Methods. We retrieved the patient data from the medical charts. Patients who were diagnosed as having EGFR-mutant NSCLC and treated with EGFR-tyrosine kinase inhibitors (EGFR-TKIs) between 2007 and 2020 at our institution were included in the analysis.

Results. A total of 130 patients were included in the analysis. A log-rank test identified EGFR exon 19 deletion in the tumor, an Eastern Cooperative Oncology Group performance status of 0-1, serum lactate dehydrogenase level, local therapy for brain metastasis, and sequential osimertinib therapy for patients with the T790M mutation acquired after primary EGFR-TKI therapy as being significantly associated with a better overall survival. Analysis using a Cox proportional hazards model identified EGFR exon 19 deletion in the tumor, an Eastern Cooperative Oncology Group performance status of 0-1, serum lactate dehydrogenase level, local therapy for brain metastasis, and sequential therapy with osimertinib as being independently associated with a prolonged overall survival.

Conclusion. Our analysis suggested that sequential therapy with osimertinib in patients with acquired drug resistance associated with the appearance of the T790M mutation after the primary EGFR-TKI therapy was associated with prolongation of the overall survival in patients with EGFR-mutant NSCLC in clinical practice settings.

\section{Introduction}

Treatment with epidermal growth factor receptor (EGFR)-tyrosine kinase inhibitors has been shown to improve the prognosis in patients with EGFR-mutant non-small cell lung cancer (NSCLC). At first, firstgeneration EGFR-TKIs were shown to prolong the progression-free survival (PFS) as compared to cytotoxic agents [1, 2]. Thereafter, afatinib, a second-generation EGFR-TKI, was shown to prolong the PFS than the first-generation EGFR-TKIs [3], and this drug yielded a longer overall survival (OS), although the difference did not reach statistical significance [4]. In a more recent trial, the PFS and OS were significantly prolonged in the osimertinib treatment arm (a third-generation EGFR-TKI) as compared to the control arm treated with a first-generation EGFR-TKI [5]. In addition to these therapeutic advances, reports have shown that about a half of the patients who are treated with a first- or second-generation EGFR-TKI develop acquired resistance to the primary EGFR-TKI therapy, associated with the emergence of the EGFR exon 20 T790M mutation [6], but that the PFS in these patients can still be prolonged by sequential therapy with osimertinib [7]. Other studies have reported that patients who developed resistance associated with the emergence of the T790M mutation after treatment with afatinib who received sequential osimertinib therapy showed an extremely prolonged OS [8, 9]. 
Based on the above, it is evident that therapeutic advances have yielded improvement of the prognosis of patients with EGFR-mutant NSCLC in clinical practice. We conducted a retrospective study to investigate the associations of the available therapeutic options with the OS in patients with EGFR-mutant NSCLC.

\section{Methods}

\section{Patient selection}

Clinical information was retrieved from the medical charts. The inclusion criteria were as follows: 1) patients with cytologically or histologically diagnosed EGFR-mutant NSCLC; 2) patients who had received EGFR-TKI therapy as the first-line treatment between 2007 and 2020 at our institution. The exclusion criteria were as follows: 1) patients in whom the exon 20 T790M mutation was detected in the tumor even prior to the start of the first-line treatment.

This retrospective study was conducted in accordance with the principles outlined in the Declaration of Helsinki and Ethics Guidelines for Medical and Health Research Involving Human Subjects (Ministry of Health, Labour and Welfare, Japan). We disclosed information about the study to the patients under the approval of the Ethics Committee, University of Toyama (approval number: R2019103).

\section{Clinical information}

The tumor EGFR mutations were classified as exon 19 deletion, exon 21 L858R, or uncommon mutations. Compound mutations with common (exon 19 deletion or exon 21 L858R) and uncommon mutations were classified as uncommon mutations.

Tumor PD-L1 expression was evaluated by immunohistochemistry in formalin-fixed and paraffinembedded tumor tissue specimens, using the 22C3 antibody (BML, Tokyo, Japan). The proportion of PDL1-positive cells in the tumor was evaluated as the tumor proportion score (TPS) for PD-L1 expression.

Local therapy for brain metastasis was defined as local therapy administered at the start of first-line treatment, and included stereotactic radiotherapy, whole-brain irradiation, and surgery.

Sequential therapy with osimertinib was defined as treatment with osimertinib for patients who developed acquired resistance to the primary EGFR-TKI therapy associated with appearance of the T790M mutation in the tumor. Re-administration of first- or second-generation EGFR-TKIs was defined as re-administration of other first- or second-generation EGFR-TKIs for patients with acquired resistance to the primary EGFR-TKIs. Changes of the EGFR-TKIs administered for other reasons such as development of adverse events associated with the initial EGFR-TKIs were not included in the above definition.

\section{Statistical analysis}

Survival curves were drawn by the Kaplan-Meier method. OS was calculated from the date of initiation of treatment with an EGFR-TKI until death, and censored at the last visit of the patient. Patient data were 
dichotomized according to categorical variables or median values of numerical variables, and the OS was compared by the log-rank test. Variables that were determined as showing an association with $\mathrm{P}$ values of $<0.2$ were selected as independent variables to be entered into the Cox proportional hazards model. All the statistical analyses were performed using JMP ver. 15.0.0 (SAS, Cary, NC).

\section{Results}

A total of 158 patients with EGFR-mutant NSCLC were treated at our institution between 2007 and 2020. Of the 158 patients, 25 patients were excluded from this analysis because they did not receive first-line EGFR-TKI treatment, and 3 patients were excluded because the T790M mutation was detected in the tumor even at initial diagnosis. Data of the remaining 130 patients with EGFR-mutant NSCLC who had been treated with EGFR-TKIs as the first-line treatment were included in this analysis. The date of death could be confirmed for 52 (40\%) patients, but not for 48 patients (36.9\%), because the latter were transferred to some other hospital prior to their death. Anticancer therapy was ongoing at the time of the analysis in this study in $30(23.1 \%)$ patients.

Table 1 shows the patient characteristics. Of the 130 patients, 84 (64.6\%), 25 (19.2\%), and 21 (16.2\%) patients received first-line treatment with a first-generation (including gefitinib and erlotinib), secondgeneration (afatinib), and third-generation (osimertinib) EGFR-TKI, respectively. Five (3.8\%) patients received combined EGFR-TKI plus vascular endothelial growth factor (VEGF) inhibitor therapy, and 36 (27.7\%) patients received platinum-doublet therapy at some point during the clinical course. Twenty-one (16.2\%) patients received sequential therapy with osimertinib, and $16(12.3 \%)$ patients received readministration of another first- or second-generation EGFR-TKI. Out of the total of 109/130 patients who did not receive sequential therapy with osimertinib, the anticancer therapy had been discontinued in 43 patients even prior to 2016, when osimertinib therapy first became available. Brain metastasis was detected at the initial diagnosis in $37(28.5 \%)$ patients, and was treated by stereotactic radiotherapy in 14 patients, stereotactic radiotherapy and surgery in 1 patient, and whole-brain irradiation in 9 patients. 
Table 1

Patient characteristics

\begin{tabular}{|c|c|c|}
\hline & & n (\%) \\
\hline \multirow[t]{2}{*}{ Age (yr) } & $<75$ & $70(53.8 \%)$ \\
\hline & $\geq 75$ & $60(46.2 \%)$ \\
\hline \multirow[t]{2}{*}{ Sex } & Male & $48(36.9 \%)$ \\
\hline & Female & $82(63.1 \%)$ \\
\hline \multirow[t]{2}{*}{ Histology } & Adenocarcinoma & $125(96.2 \%)$ \\
\hline & Others & $5(3.8 \%)$ \\
\hline \multirow[t]{3}{*}{ EGFR mutation } & Exon 19 del & $56(43.1 \%)$ \\
\hline & Exon 21 L858R & $62(47.7 \%)$ \\
\hline & Uncommon mutation & $12(9.2 \%)$ \\
\hline \multirow[t]{2}{*}{ PS } & $0-1$ & $93(71.5 \%)$ \\
\hline & $\geq 2$ & $37(28.5 \%)$ \\
\hline \multirow[t]{2}{*}{$\mathrm{LDH}(\mathrm{U} / \mathrm{L})$} & $<200$ & $58(44.6 \%)$ \\
\hline & $\geq 200$ & $72(55.4 \%)$ \\
\hline \multirow[t]{3}{*}{ Tumor PD-L1 TPS } & $\geq 1 \%$ & $36(27.7 \%)$ \\
\hline & $<1 \%$ & $24(18.5 \%)$ \\
\hline & Unknown & $70(53.8 \%)$ \\
\hline \multirow[t]{2}{*}{ History of surgery } & Yes & $22(16.8 \%)$ \\
\hline & No & $109(83.2 \%)$ \\
\hline \multirow[t]{2}{*}{ Brain metastasis } & Yes & $37(28.5 \%)$ \\
\hline & No & $93(71.5 \%)$ \\
\hline \multirow[t]{3}{*}{ First-line EGFR-TKI used } & 1st generation TKIs & $84(64.6 \%)$ \\
\hline & Afatinib & $25(19.2 \%)$ \\
\hline & Osimertinib & $21(16.2 \%)$ \\
\hline History of platinum-doublet therapy & Yes & $36(27.7 \%)$ \\
\hline
\end{tabular}

EGFR, epidermal growth factor receptor; ICl, immune checkpoint inhibitor; LDH, serum lactate dehydrogenase; PD-L1, programmed death ligand 1; PS, performance status; TKI, tyrosine kinase inhibitor; TPS, tumor proportion score; VEGF, vascular endothelial growth factor. 


\begin{tabular}{|lll|}
\hline & & $\mathbf{n}(\%)$ \\
\hline History of VEGF inhibitor therapy & No & $94(72.3 \%)$ \\
\hline Sequential therapy with TKIs & Yes & $5(3.8 \%)$ \\
\cline { 2 - 3 } & No & $125(96.2 \%)$ \\
\hline & Osimertinib & $21(16.2 \%)$ \\
\hline History of ICl therapy & 1st/2nd generation TKIs & $16(12.3 \%)$ \\
\hline & None & $93(71.5 \%)$ \\
\hline $\begin{array}{l}\text { EGFR, epidermal growth factor receptor; ICl, immune checkpoint inhibitor; LDH, serum lactate } \\
\text { dehydrogenase; PD- } 1 \text { 1, programmed death ligand 1; PS, performance status; TKI, tyrosine kinase } \\
\text { inhibitor; TPS, tumor proportion score; VEGF, vascular endothelial growth factor. }\end{array}$ & $13(10.0 \%)$ \\
\hline
\end{tabular}

Table 2 shows the association between the patient characteristics and the OS as determined by the logrank test; comparison by the log-rank test identified exon 19 deletion in the tumor, and Eastern Cooperative Oncology Group (ECOG) performance status (PS) of $0-1$, a serum lactate dehydrogenase $(\mathrm{LDH})$ level of $<200 \mathrm{U} / \mathrm{L}$, and sequential therapy with osimertinib as being associated with a prolonged OS. Figure 1 shows the Kaplan-Meier curves for OS in patients who did and did not receive sequential therapy with osimertinib. The OS duration was longer (median, 78.5 months) in patients who had received sequential therapy with osimertinib as compared to those who had received re-administration of first- or second-generation EGFR-TKIs (median, 31.5 months) and patients who had received neither of the above (median, 33.0 months) $(P=0.019$, log-rank test). 
Table 2

Associations of the patient characteristics with the OS (log-rank test)

\begin{tabular}{|c|c|c|c|c|}
\hline & & $\begin{array}{l}\text { OS } \\
\text { (median) }\end{array}$ & $95 \% \mathrm{Cl}$ & $P$ \\
\hline \multirow[t]{2}{*}{ Age (yr) } & $<75$ & 40.0 & 31.5-NE & 0.523 \\
\hline & $\geq 75$ & 34.0 & $\begin{array}{l}25.5- \\
52.7\end{array}$ & \\
\hline \multirow[t]{2}{*}{ Sex } & Male & 33.1 & $\begin{array}{l}20.5- \\
46.8\end{array}$ & 0.254 \\
\hline & Female & 52.7 & 30.4-NE & \\
\hline \multirow[t]{2}{*}{ Histology } & Adenocarcinoma & 40.0 & $\begin{array}{l}31.5- \\
54.7\end{array}$ & 0.931 \\
\hline & Others & 32.3 & $\begin{array}{l}22.6- \\
32.3\end{array}$ & \\
\hline \multirow[t]{3}{*}{ EGFR mutation } & Exon 19 del & NR & 33.1-NE & 0.011 \\
\hline & Exon 21 L858R & 40.0 & $\begin{array}{l}22.6- \\
52.7\end{array}$ & \\
\hline & Uncommon mutation & 32.3 & 5.3-NE & \\
\hline \multirow[t]{2}{*}{ PS } & $0-1$ & 52.7 & $34.0-87.6$ & 0.002 \\
\hline & $\geq 2$ & 30.4 & $\begin{array}{l}10.3- \\
40.0\end{array}$ & \\
\hline \multirow[t]{2}{*}{$\mathrm{LDH}(\mathrm{U} / \mathrm{L})$} & $<200$ & 51.3 & $34.0-78.5$ & 0.046 \\
\hline & $\geq 200$ & 28.6 & 17.2-NE & \\
\hline \multirow[t]{3}{*}{ PD-L1 TPS } & $\geq 1 \%$ & 51.3 & $\begin{array}{l}32.3- \\
87.6\end{array}$ & 0.394 \\
\hline & $<1 \%$ & 46.8 & $\begin{array}{l}30.4- \\
78.5\end{array}$ & \\
\hline & Unknown & 31.5 & 19.4-NE & \\
\hline \multirow[t]{2}{*}{ History of surgery } & Yes & NR & 28.3-NE & 0.184 \\
\hline & No & 38.8 & $\begin{array}{l}28.6- \\
52.7\end{array}$ & \\
\hline Brain metastasis & Yes (with local therapy) & NR & 36.1-NE & 0.033 \\
\hline
\end{tabular}

$\mathrm{Cl}$, confidence interval; EGFR, epidermal growth factor receptor; ICl, immune checkpoint inhibitor; LDH, serum lactate dehydrogenase; NE, not estimated; PD-L1, programmed death ligand 1; PS, performance status; TKI, tyrosine kinase inhibitor; TPS, tumor proportion score; VEGF, vascular endothelial growth factor. 


\begin{tabular}{|c|c|c|c|c|}
\hline & & $\begin{array}{l}\text { OS } \\
\text { (median) }\end{array}$ & $95 \% \mathrm{Cl}$ & $\mathbf{P}$ \\
\hline & $\begin{array}{l}\text { Yes (without local } \\
\text { therapy) }\end{array}$ & 17.2 & 5.3-NE & \\
\hline & No & 34.0 & $\begin{array}{l}28.6- \\
52.7\end{array}$ & \\
\hline \multirow[t]{3}{*}{ First-line TKI used } & 1st generation TKIs & 36.1 & $28.0-51.3$ & 0.157 \\
\hline & Afatinib & NR & 19.2-NE & \\
\hline & Osimertinib & NR & 20.5-NE & \\
\hline \multirow{2}{*}{$\begin{array}{l}\text { History of platinum-doublet } \\
\text { therapy }\end{array}$} & Yes & 40.3 & 28.6-NE & 0.470 \\
\hline & No & 34.0 & $\begin{array}{l}28.3- \\
87.6\end{array}$ & \\
\hline \multirow[t]{2}{*}{ History of VEGF inhibitor therapy } & Yes & 54.7 & $11.0-54.7$ & 0.895 \\
\hline & No & 38.8 & $\begin{array}{l}30.4- \\
78.5\end{array}$ & \\
\hline \multirow[t]{3}{*}{ Sequential therapy with TKIs } & Osimertinib & 78.5 & 46.8-NE & 0.019 \\
\hline & 1st/2nd generation TKls & 31.5 & 13.0-NE & \\
\hline & None & 33.0 & $\begin{array}{l}22.6- \\
38.8\end{array}$ & \\
\hline \multirow[t]{2}{*}{ History of ICl therapy } & Yes & 54.7 & 18.7-NE & 0.389 \\
\hline & No & 36.1 & $\begin{array}{l}28.6- \\
78.5\end{array}$ & \\
\hline \multicolumn{5}{|c|}{$\begin{array}{l}\mathrm{Cl} \text {, confidence interval; EGFR, epidermal growth factor receptor; ICI, immune checkpoint inhibitor; } \mathrm{LDH} \text {, } \\
\text { serum lactate dehydrogenase; NE, not estimated; PD-L1, programmed death ligand 1; PS, performance } \\
\text { status; TKI, tyrosine kinase inhibitor; TPS, tumor proportion score; VEGF, vascular endothelial growth } \\
\text { factor. }\end{array}$} \\
\hline
\end{tabular}

Table 3 shows the results of the analysis conducted using a Cox proportional hazards model conducted to identify the factors influencing the OS. The analysis identified the type of EGFR mutation in the tumor, the ECOG PS, the serum LDH level, treatment status for brain metastasis, and sequential therapy with osimertinib as factors that significantly influenced the OS. First-line treatment with afatinib or osimertinib showed a risk reduction versus treatment with a first-generation TKI, although the difference did not reach statistical significance. 
Table 3

Associations of the patient characteristics with the OS (Cox proportional hazard model)

\begin{tabular}{|c|c|c|c|}
\hline & & HR & $\mathbf{P}$ \\
\hline \multirow[t]{3}{*}{ EGFR mutation } & Exon 19 del & $0.40(0.21-0.78)$ & 0.007 \\
\hline & Exon 21 L858R & 1.00 & \\
\hline & Uncommon mutation & $0.83(0.32-2.13)$ & 0.699 \\
\hline \multirow[t]{2}{*}{ PS } & $0-1$ & $035(0.18-0.67)$ & 0.002 \\
\hline & $\geq 2$ & 1.00 & \\
\hline \multirow[t]{2}{*}{$\mathrm{LDH}(\mathrm{U} / \mathrm{L})$} & $<200$ & $0.43(0.23-0.82)$ & 0.011 \\
\hline & $\geq 200$ & 1.00 & \\
\hline \multirow[t]{2}{*}{ History of surgery } & Yes & $0.77(0.33-1.83)$ & 0.557 \\
\hline & No & 1.00 & \\
\hline \multirow[t]{3}{*}{ Brain metastasis } & Yes (with local therapy) & $0.18(0.05-0.65)$ & 0.008 \\
\hline & Yes (without local therapy) & 1.00 & \\
\hline & No & $0.68(0.28-1.62)$ & 0.384 \\
\hline \multirow[t]{3}{*}{ First-line TKI used } & 1st generation TKIs & 1.00 & \\
\hline & Afatinib & $0.50(0.21-1.20)$ & 0.120 \\
\hline & Osimertinib & $0.37(0.10-1.29)$ & 0.119 \\
\hline \multirow[t]{3}{*}{ Sequential therapy with TKIs } & Osimertinib & $0.25(0.11-0.60)$ & 0.002 \\
\hline & 1st/2nd generation TKls & $1.01(0.44-2.33)$ & 0.973 \\
\hline & None & 1.00 & \\
\hline
\end{tabular}

\section{Discussion}

In the present study, we showed that sequential therapy with osimertinib in EGFR-mutant NSCLC patients with acquired T790M mutation was associated with a longer OS. Furthermore, the hazard ratio for death was lower in patients who received afatinib or osimertinib as first-line treatment than in patients who received first-generation EGFR-TKIs as the first-line treatment, although the difference did not reach statistical significance. 
The AURA study demonstrated that osimertinib yielded a longer PFS as compared to platinum-doublet therapy in patients with acquired resistance to primary EGFR-TKI therapy associated with emergence of the T790M mutation [7]. Therefore, the effectiveness of osimertinib for patients with acquired T790M mutation might be reflected in the results of the present study, with improvement of the prognosis of EGFR-mutant NSCLC with clinical application of sequential osimertinib therapy. However, it has also been reported that patients with acquired resistance to primary EGFR-TKI therapy associated with the emergence of the T790M mutation showed a longer PFS of first-line EGFR-TKI treatment [10-13], and a lower incidence of brain metastasis under the treatment not including osimertinib [14]. Therefore, in addition to the effectiveness of osimertinib, the selection of T790M-positive patients after first-line EGFRTKI treatment might have resulted in the selection of patients with a favorable prognosis, resulting in a longer survival.

In the FLAURA trial, patients with untreated EGFR-mutant NSCLC who received first-line osimertinib treatment showed a significantly longer OS as compared to patients who received first-generation EGFRTKIs as the first-line treatment [5]. However, a subset analysis revealed that there was no clear evidence of prolongation of the OS in the osimertinib arm in the Asian as compared to the non-Asian subset of patients. The effectiveness of first-line treatment with osimertinib in Asians may be an issue that warrants further investigation in the future. In the present study, multivariate analysis revealed no significant association between the type of EGFR-TKI used for first-line treatment and the OS. This could be because some patients in whom the first-/second-generation EGFR-TKIs were changed to osimertinib due to the appearance of side effects rather than due to acquired resistance to the EGFR-TKIs have been included in the first- or second-generation EGFR-TKI group. In addition, the number of patients who were treated with osimertinib as first-line treatment was very small $(n=21)$, which could have led to a lack of statistical power.

Analysis of the OS data from the LUX-Lung 3, LUX-Lung 6 [15], and FLAURA [5] trials showed that the study treatment was more beneficial in patients with tumors carrying the exon 19 deletion as compared to exon $21 \mathrm{~L} 858 \mathrm{R}$ as the EGFR mutation. The results of the present study showed that the hazard ratio for death was lower in patients with tumors carrying the exon 19 deletion. It is considered that the higher efficacy of EGFR-TKIs in patients with tumors carrying the exon 19 deletion might have contributed to the results of the present study.

Two previous studies have reported that combined therapy with erlotinib, a first-generation EGFR-TKI, plus a VEGF inhibitor yielded a longer PFS as compared to erlotinib monotherapy [16, 17]. However, in both of these clinical trials, the PFS, but not the OS, was compared as the primary endpoint. Furthermore, a metaanalysis demonstrated that combined erlotinib plus VEGF inhibitor therapy was associated with a longer PFS, but no prolongation of the OS in patients with EGFR-mutant NSCLC [18]. In the present study, comparison by the log-rank test showed no association between combined first-generation EGFR-TKI plus VEGF inhibitor therapy and the OS, although no definitive conclusions can be drawn because of the retrospective nature of the study and the small number of patients who received the combination therapy. 
Numerous studies have reported serum LDH as a prognostic factor, and indicated an association of the serum LDH with the OS in patients with NSCLC, whether treated by EGFR-TKI therapy [19], cytotoxic chemotherapy, or best supportive care [20]. As the mechanisms underlying this association, it is considered that tumor hypoxia is linked to glycolytic enzymes and angiogenetic factors, including LDH and VEGF, and that the invasive ability and angiogenic capability of tumors is promoted by acidification of the extracellular space induced by lactic acid [21, 22].

Development of brain metastasis has been reported to influence to clinical course of patients with EGFRmutant NSCLC [14] [23]. In the present study, out of 37 patients with brain metastasis, 24 had received local therapy for brain metastasis. According to one previous report, the OS was longer in patients with brain metastasis who were treated with upfront radiotherapy as compared to systemic chemotherapy [24]. Because of the retrospective nature of our study, it would be difficult to exclude selection bias to definitively establish the superiority of the treatment option used in the present study. However, the present study findings do suggest that local therapy for brain metastasis might indeed prolong the survival in patients with EGFR-mutant NSCLC who develop brain metastasis.

There were several limitations of the present study. First, because of the retrospective nature of the study design, selection bias could have affected the results. Second, the survival rate might have been overestimated because of censoring of the patients when they were transferred to another hospital due to worsening of the general status. Third, none of the patients in this study had received combined therapy with gefitinib and cytotoxic agents, even though combined gefitinib plus chemotherapy has also been reported to yield a longer survival as compared to EGFR-TKI monotherapy [25]. Thus, we could not evaluate the association between this therapy and the patient survival.

In conclusion, the present study showed that patients developing acquired resistance to EGFR-TKI therapy associated with the emergence of the T790M mutation who received sequential therapy with osimertinib showed a longer OS than patients who did not receive sequential therapy with osimertinib. Our findings indicate that the development of new therapeutic strategies has led to improved prognosis of patients with EGFR-mutant NSCLC in the clinical setting.

\section{Declarations}

Funding: None

Competing interests: None

Availability of data and materials: The datasets used during the current study are available from the corresponding author on reasonable request.

Authors' contributions: Ml contributed to the conception and design of the work, and data analysis. Data collection was performed by MI, MM, IM, KH, ZS, KT (Kotaro Tokui), CT, SO, KK, SI, TM, RH, and SM. The 
interpretation of the data and revision of the manuscript were performed by MI, MM, IM, KH, ZS, KT (Kotaro Tokui), CT, SO, KK, SI, TM, RH, SM, and KT (Kazuyuki Tobe).

\section{Ethics approval}

The study was conducted under the approval of the Ethics Committee, University of Toyama (approval number: R2019103).

Consent to participate/Consent for publication: The informed consent was waived and we disclosed the study information, under the approval of the Ethics Committee, University of Toyama (approval number: R2019103).

\section{References}

1. Maemondo M, Inoue A, Kobayashi K, Sugawara S, Oizumi S, Isobe H et al (2010) Gefitinib or chemotherapy for non-small-cell lung cancer with mutated EGFR. N Engl J Med 362:2380-2388. https://doi.org/10.1056/NEJMoa0909530

2. Mitsudomi T, Morita S, Yatabe Y, Negoro S, Okamoto I, Tsurutani J et al (2010) Gefitinib versus cisplatin plus docetaxel in patients with non-small-cell lung cancer harbouring mutations of the epidermal growth factor receptor (WJTOG3405): an open label, randomised phase 3 trial. The Lancet Oncology 11:121-128. https://doi.org/10.1016/s1470-2045(09)70364-x

3. Park K, Tan E-H, O'Byrne K, Zhang L, Boyer M, Mok T et al (2016) Afatinib versus gefitinib as firstline treatment of patients with EGFR mutation-positive non-small-cell lung cancer (LUX-Lung 7): a phase 2B, open-label, randomised controlled trial. The Lancet Oncology 17:577-589. https://doi.org/10.1016/s1470-2045(16)30033-x

4. Paz-Ares L, Tan EH, O'Byrne K, Zhang L, Hirsh V, Boyer M et al (2017) Afatinib versus gefitinib in patients with EGFR mutation-positive advanced non-small-cell lung cancer: overall survival data from the phase Ilb LUX-Lung 7 trial. Ann Oncol 28:270-277. https://doi.org/10.1093/annonc/mdw611

5. Ramalingam SS, Vansteenkiste J, Planchard D, Cho BC, Gray JE, Ohe Y et al (2020) Overall Survival with Osimertinib in Untreated, EGFR-Mutated Advanced NSCLC. N Engl J Med 382:41-50. https://doi.org/10.1056/NEJMoa1913662

6. Kosaka T, Yatabe Y, Endoh H, Yoshida K, Hida T, Tsuboi M et al (2006) Analysis of epidermal growth factor receptor gene mutation in patients with non-small cell lung cancer and acquired resistance to gefitinib. Clin Cancer Res 12:5764-5769. https://doi.org/10.1158/1078-0432.CCR-06-0714

7. Mok TS, Wu YL, Ahn MJ, Garassino MC, Kim HR, Ramalingam SS et al (2017) Osimertinib or Platinum-Pemetrexed in EGFR T790M-Positive Lung Cancer. N Engl J Med 376:629-640. https://doi.org/10.1056/NEJMoa1612674 
8. Park K, Bennouna J, Boyer M, Hida T, Hirsh V, Kato T et al (2019) Sequencing of therapy following first-line afatinib in patients with EGFR mutation-positive non-small cell lung cancer. Lung Cancer 132:126-131. https://doi.org/10.1016/j.lungcan.2019.04.014

9. Hochmair MJ, Morabito A, Hao D, Yang CT, Soo RA, Yang JC et al (2020) Sequential afatinib and osimertinib in patients with EGFR mutation-positive non-small-cell lung cancer: final analysis of the GioTag study. Future Oncol 16:2799-2808. https://doi.org/10.2217/fon-2020-0740

10. Oya Y, Yoshida T, Kuroda H, Shimizu J, Horio Y, Sakao Y et al (2017) Association Between EGFR T790M Status and Progression Patterns During Initial EGFR-TKI Treatment in Patients Harboring EGFR Mutation. Clin Lung Cancer 18:698-705 e692. https://doi.org/10.1016/j.cllc.2017.05.004

11. Huang YH, Hsu KH, Tseng JS, Chen KC, Hsu CH, Su KY et al (2018) The Association of Acquired T790M Mutation with Clinical Characteristics after Resistance to First-Line Epidermal Growth Factor Receptor Tyrosine Kinase Inhibitor in Lung Adenocarcinoma. Cancer Res Treat 50:1294-1303. https://doi.org/10.4143/crt.2017.512

12. Joo JW, Hong MH, Shim HS (2018) Clinical characteristics of T790M-positive lung adenocarcinoma after resistance to epidermal growth factor receptor-tyrosine kinase inhibitors with an emphasis on brain metastasis and survival. Lung Cancer 121:12-17. https://doi.org/10.1016/j.lungcan.2018.04.013

13. Kawamura T, Kenmotsu H, Omori S, Nakashima K, Wakuda K, Ono A et al (2018) Clinical Factors Predicting Detection of T790M Mutation in Rebiopsy for EGFR-Mutant Non-small-cell Lung Cancer. Clin Lung Cancer 19:e247-e252. https://doi.org/10.1016/j.cllc.2017.07.002

14. Hata A, Katakami N, Yoshioka H, Takeshita J, Tanaka K, Masago K et al (2015) Prognostic impact of central nervous system metastases after acquired resistance to EGFR-TKI: poorer prognosis associated with T790M-negative status and leptomeningeal metastases. Anticancer Res 35:1025-1031.

15. Yang JC-H, Wu Y-L, Schuler M, Sebastian M, Popat S, Yamamoto $\mathrm{N}$ et al (2015) Afatinib versus cisplatin-based chemotherapy for EGFR mutation-positive lung adenocarcinoma (LUX-Lung 3 and LUXLung 6): analysis of overall survival data from two randomised, phase 3 trials. The Lancet Oncology 16:141-151. https://doi.org/10.1016/s1470-2045(14)71173-8

16. Saito H, Fukuhara T, Furuya N, Watanabe K, Sugawara S, Iwasawa S et al (2019) Erlotinib plus bevacizumab versus erlotinib alone in patients with EGFR-positive advanced non-squamous non-smallcell lung cancer (NEJ026): interim analysis of an open-label, randomised, multicentre, phase 3 trial. The Lancet Oncology 20:625-635. https://doi.org/10.1016/s1470-2045(19)30035-x

17. Nakagawa K, Garon EB, Seto T, Nishio M, Ponce Aix S, Paz-Ares L et al (2019) Ramucirumab plus erlotinib in patients with untreated, EGFR-mutated, advanced non-small-cell lung cancer (RELAY): a 
randomised, double-blind, placebo-controlled, phase 3 trial. Lancet Oncol 20:1655-1669. https://doi.org/10.1016/s1470-2045(19)30634-5

18. Landre T, Des Guetz G, Chouahnia K, Duchemann B, Assié JB, Chouaid C (2020) First-line angiogenesis inhibitor plus erlotinib versus erlotinib alone for advanced non-small-cell lung cancer harboring an EGFR mutation. J Cancer Res Clin Oncol 146:3333-3339. https://doi.org/10.1007/s00432020-03311-w

19. Inomata M, Hayashi R, Tanaka H, Shimokawa K, Tokui K, Taka C et al (2016) Elevated levels of plasma lactate dehydrogenase is an unfavorable prognostic factor in patients with epidermal growth factor receptor mutation-positive non-small cell lung cancer, receiving treatment with gefitinib or erlotinib. Mol Clin Oncol 4:774-778. https://doi.org/10.3892/mco.2016.779

20. Ulas A, Turkoz FP, Silay K, Tokluoglu S, Avci N, Oksuzoglu B et al (2014) A laboratory prognostic index model for patients with advanced non-small cell lung cancer. PLoS One 9:e114471. https://doi.org/10.1371/journal.pone.0114471

21. Koukourakis MI, Giatromanolaki A, Sivridis E, Bougioukas G, Didilis V, Gatter KC et al (2003) Lactate dehydrogenase-5 (LDH-5) overexpression in non-small-cell lung cancer tissues is linked to tumour hypoxia, angiogenic factor production and poor prognosis. Br J Cancer 89:877-885. https://doi.org/10.1038/sj.bjc.6601205

22. Danner BC, Didilis VN, Wiemeyer S, Stojanovic T, Kitz J, Emmert A et al (2010) Long-term survival is linked to serum LDH and partly to tumour LDH-5 in NSCLC. Anticancer Res 30:1347-1351.

23. Jain A, Lim C, Gan EM, Ng DZ, Ng QS, Ang MK et al (2015) Impact of Smoking and Brain Metastasis on Outcomes of Advanced EGFR Mutation Lung Adenocarcinoma Patients Treated with First Line Epidermal Growth Factor Receptor Tyrosine Kinase Inhibitors. PLoS One 10:e0123587. https://doi.org/10.1371/journal.pone.0123587

24. Magnuson WJ, Yeung JT, Guillod PD, Gettinger SN, Yu JB, Chiang VL (2016) Impact of Deferring Radiation Therapy in Patients With Epidermal Growth Factor Receptor-Mutant Non-Small Cell Lung Cancer Who Develop Brain Metastases. Int J Radiat Oncol Biol Phys 95:673-679. https://doi.org/10.1016/j.ijrobp.2016.01.037

25. Hosomi Y, Morita S, Sugawara S, Kato T, Fukuhara T, Gemma A et al (2020) Gefitinib Alone Versus Gefitinib Plus Chemotherapy for Non-Small-Cell Lung Cancer With Mutated Epidermal Growth Factor Receptor: NEJ009 Study. J Clin Oncol 38:115-123. https://doi.org/10.1200/JC0.19.01488

\section{Figures}




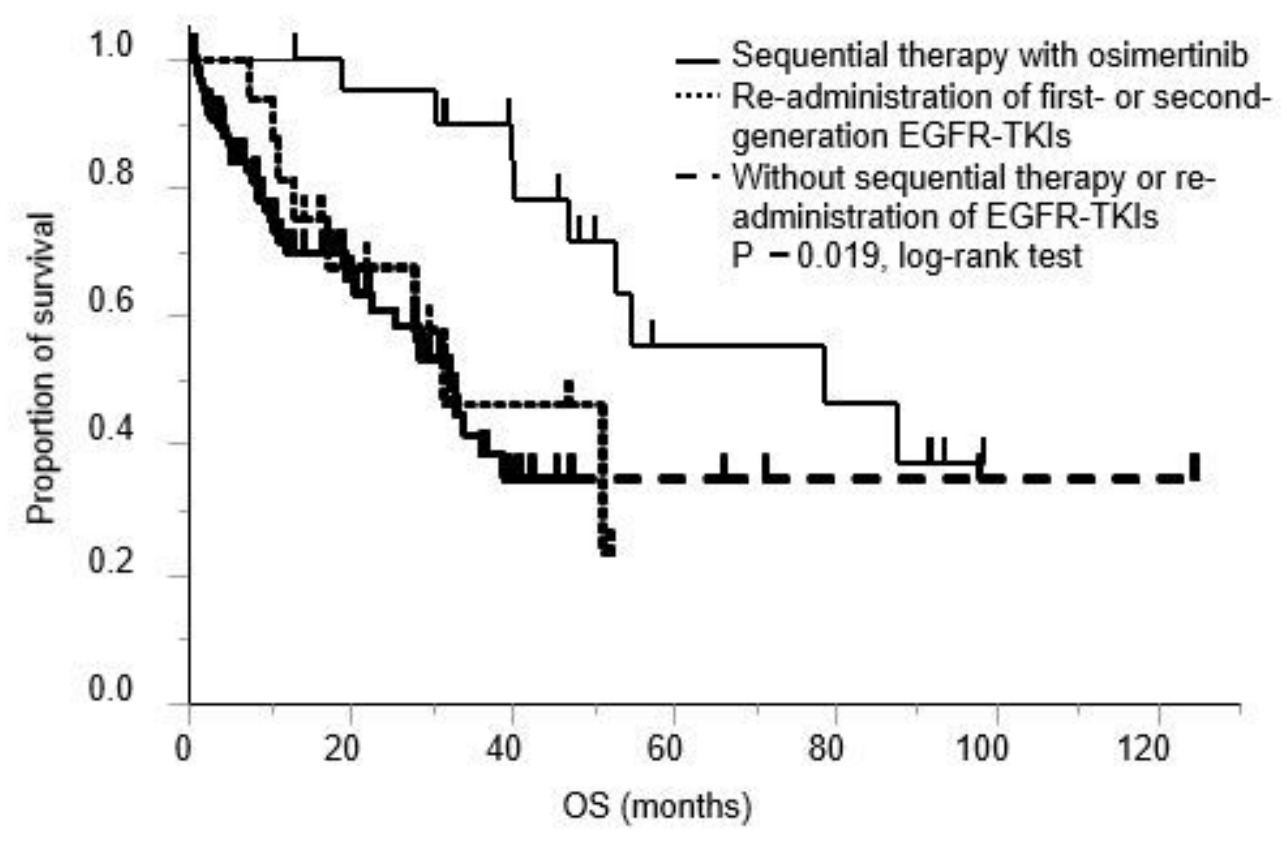

\section{Figure 1}

Kaplan-Meier curve for OS in patients who received sequential therapy with osimertinib, who received readministration of the first-/second-generation EGFR-TKIs, and who received neither of the above. Solid line: patient group that received sequential therapy with osimertinib; dotted line: patient group that received re-administration of first-/second-generation EGFR-TKIs; dashed line: patients who neither received neither sequential therapy with osimertinib, nor re-administration of first-/second-generation EGFR-TKIs. 